\title{
ANALISA KEBUTUHAN MAKE UP WATER COOLING TOWER RSG-GAS PADA DAYA 30 MW SETELAH REVITALISASI
}

\author{
Pranto Busono1, Santosa Pujiarta² \\ 12 PRSG - BATAN Kawasan Puspiptek Gd. 31 Serpong, 15310 \\ email: pranto@batan.go.id
}

Diterima: 23 Januari 2020, diperbaiki : 6 Febuari 2020, disetujui : 13 April 2020

\begin{abstract}
ABSTRAK
ANALISA KEBUTUHAN MAKE UP WATER COOLING TOWER RSG-GAS PADA DAYA 30 MW SETELAH REVITALISASI. Akibat kondisi dan usia dari cooling tower RSG-GAS maka telah dilakukan revitalisasi pada cooling tower tersebut. Cooling tower yang baru mempunyai tipe sama dengan tipe sebelumnya, yaitu tipe Mechanical induced draft, counter flow, Inline, Closed end. Akibat penggantian/revitalisasi cooling tower RSG-GAS maka perlu dilakukan kajian yang berkaitan dengan besarnya kehilangan air. Kehilangan air pada cooling tower terdiri atas: evaporation loss $(W e)$, Drift loss $(W d)$ dan blowdown $(W b)$. Besarnya kehilangan air berdasarkan desain $93,8074 \mathrm{~m}^{3} / \mathrm{h}$, hasil perhitungan $53,1286 \mathrm{~m}^{3} / \mathrm{h}$ dan hasil pengamatan adalah sebesarnya $39,4548 \mathrm{~m}^{3} / \mathrm{h}$. Kehilangan air pada cooling tower perlu diperhitungkan karena berkaitan dengan kemampuan pompa PA-04 dalam mengkompensasi kehilangan air tersebut. Dengan kemampuan pompa PA-04 yang mempunyai kapasitas $100 \mathrm{~m}^{3} / \mathrm{h}$, maka dapat dipastikan bahwa pompa PA-04 masih mampu untuk mengkompensasi kehilangan air di cooling tower.
\end{abstract}

Kata kunci : make up water, revitalisasi cooling tower, kehilangan air

\begin{abstract}
ANALYSIS OF NEEDS MAKE UP WATER COOLING TOWER RSG-GAS AT 30 MW POWER AFTER REVITALIZATION. Due to the condition and age of the RSG-GAS cooling tower, revitalization of the cooling tower has been carried out. The new cooling tower has the same type as the previous type, namely Mechanical induced draft, counter flow, Inline, Closed end types. As a result of the replacement or revitalization of the RSG-GAS cooling tower, it is necessary to conduct a study related to the amount of water loss. Water loss in a cooling tower consists of: evaporation loss $(W e)$, Drift loss (Wd) and blowdown (Wb). The amount of water loss based on the design is $93.8074 \mathrm{~m}^{3} / \mathrm{h}$, the calculation result is $53.1286 \mathrm{~m}^{3} / \mathrm{h}$ and the observation result is $39.4548 \mathrm{~m}^{3} / \mathrm{h}$. The loss of water in the cooling tower needs to be taken into account because it is related to the PA-04 pump's ability to compensate for the water loss. With the PA-04 pump's capacity which has a capacity of $100 \mathrm{~m}^{3} / \mathrm{h}$, it is certain that the PA-04 pump is still able to compensate for the loss of water in the cooling tower.
\end{abstract}

Keywords: make up water, cooling tower revitalization, water loss

\section{PENDAHULUAN}

Secara garis besar pembuangan panas hasil reaksi fisi di teras reaktor RSG-GAS ke lingkungan, dilakukan melalui dua tahapan, yaitu melalui sistem pendingin primer dan sistem pendingin sekunder. Panas hasil reaksi fisi di teras reaktor dipindahkan melalui sistem pendingin primer menuju heat exchanger. Pada bagian heat exchanger tersebut sistem pendingin primer dan sistem pendingin sekunder bertemu sehingga panas tersebut dapat 
berpindah ke sistem pendingin sekunder dan akan dibuang ke lingkungan melalui cooling tower.

Mengingat usia cooling tower RSGGAS sudah lebih dari 30 tahun sehingga kurang optimal dalam membuang panas ke lingkungan, sebagai tindaklanjutnya pada tahun 2018 telah dilakukan revitalisasi. Cooling tower yang baru memiliki tipe sama dengan cooling tower di RSG-GAS sebelumnya, hanya terdapat beberapa perbedaan, antara lain: cooling tower yang baru lebih tinggi, jumlah blade lebih banyak, gearbox dan sistem transmisinya, serta sistem distribusi air. Cooling tower yang baru adalah tipe mechanical induced draft, counter flow, Inline, Closed end. ${ }^{[1]}$ Pada tipe mechanical induced draft maka pertukaran panas antara fluida pendingin dan udara terjadi secara induksi pada menara. Akibatnya udara yang berisi uap air yang dihasilkan dari pertukaran panas sebagian akan terbuang ke atmosfer. Kehilangan uap air inilah yang harus dikompensasi oleh sistem make up water dan dilakukan dengan cara menambah air dari kolam raw water dengan menggunakan pompa PA-04.

Akibat dari penggantian/ revitalisasi cooling tower RSG-GAS tersebut maka perlu dilakukan kajian yang berkaitan dengan:

- Besarnya kehilangan air yang diakibatkan adanya penguapan dan percikan pada cooling tower yang baru.

- Perhitungan kemampuan pompa PA04 dalam mengkompensasi kehilangan air tersebut.

Tujuan dari penulisan ini yaitu untuk melakukan kajian tentang kehilangan air pada cooling tower, menghitung kemampuan pompa make up (PA-04 AP001/002) dalam mengatasi kehilangan air serta membandingkan antara hasil perhitungan dengan kondisi sebenarnya.

Dalam makalah ini akan dikerjakan :

- Melakukan perhitungan kehilangan air di cooling tower akibat penguapan dan percikan.

- Melakukan perhitungan waktu yang diperlukan untuk memenuhi kehilangan uap air untuk menentukan apakah pompa PA-04 masih mampu untuk mengatasi kehilangan air tersebut.

\section{TEORI}

Cooling Tower didefinisikan sebagai alat penukar kalor yang fluida kerjanya adalah air dan udara. Cooling Tower berfungsi mendinginkan air melalui kontak langsung dengan udara yang mengakibatkan sebagian kecil air menguap. Kemampuan cooling tower dalam menghasilkan air pendingin biasanya dinyatakan dalam range dan approach seperti yang terlihat pada gambar dibawah ini::[2][3]

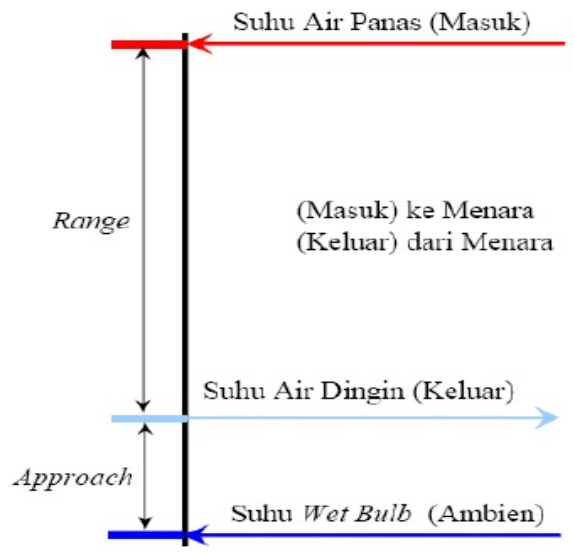

Gambar 1. Gambaran suhu di cooling tower

Range adalah perbedaan suhu antara tingkat suhu air masuk cooling tower dengan tingkat suhu air yang keluar cooling tower atau selisih antara suhu air 
panas dan suhu air dingin. Approach adalah perbedaan antara suhu air keluar cooling tower dengan suhu bola basah udara yang masuk atau selisih antara suhu air dingin dan suhu bola basah (wet bulb) dari udara. ${ }^{[4][5]}$

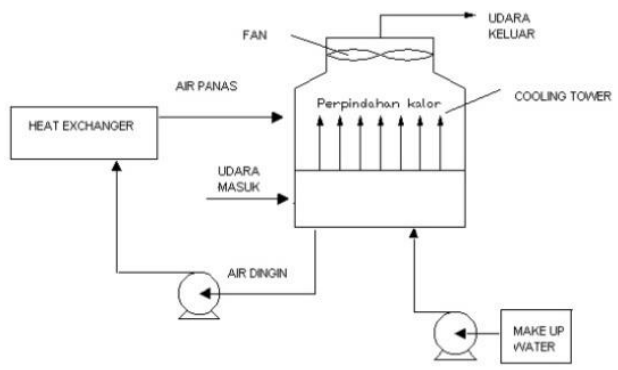

Gambar 2. Prinsip kerja sistem pendingin sekunder dan cooling tower

Air dari kolam cooling tower dipompa menuju heat exchanger untuk mengambil panas dari sistem primer dan selanjutnya air dalam kondisi panas yang berasal dari heat exchanger dialirkan menuju cooling tower. Air panas tersebut akan berkontak langsung dengan udara sekitar yang bergerak pada sisi bagian atas cooling tower karena pengaruh dari fan atau blower dan air yang memiliki suhu lebih dingin akan jatuh ke kolam cooling tower. Dari proses ini akan menghasilkan suhu yang rendah yaitu hampir mendekati suhu bola basah udara. Air yang sudah mengalami penurunan suhu ditampung ke kolam.

Cooling tower menggunakan prinsip penguapan dimana sebagian air diuapkan ke aliran udara yang bergerak dan kemudian dibuang ke lingkungan. Dalam pengoperasian cooling tower dimungkinkan terjadi kehilangan air sehingga diperlukan penambahan air untuk menjaga kestabilan jumlah air yang bersirkulasi. Kehilangan air diakibatkan oleh beberapa faktor yaitu evaporation loss (We), drift loss (Wd) dan blowdown (Wb), ${ }^{[6][7]}$ sehingga pada cooling tower pengurangan air yang sangat signifikan, harus dikompensasi dengan pompa make-up. ${ }^{[8]}$ Pada sistem pendingin sekunder PRSG, untuk mengatasi kekurangan volume air di cooling tower, disediakan pompa make up water PA-04.

Evaporation loss (We) adalah kehilangan air akibat penguapan sebagian kecil air karena adanya pemanasan. Besarnya nilai evaporation loss dari desain ditentukan sebagai berikut:

$$
\mathrm{We}=1,15 \% \times \mathrm{Wc} \ldots \ldots \ldots \ldots \ldots(1)^{[7]}
$$

Keterangan :

We $=$ Evaporation loss $\left(\mathrm{m}^{3} / \mathrm{hr}\right)$

$\mathrm{Wc}=$ Cooling tower water flow $\left(\mathrm{m}^{3} / \mathrm{hr}\right)$

Sedangkan pendekatan lain untuk perhitungan evaporation loss menurut Cooling Tower Make up Water ${ }^{[2]}$, banyaknya jumlah air yang hilang akibat penguapan atau evaporation loss (We) dapat dihitung menggunakan persamaan dibawah ini :

$$
W e=0,00085 \mathrm{Wc}\left(\mathrm{T}_{2}-\mathrm{T}_{1}\right)
$$

Keterangan :

Wc = Debit air saat pengukuran $\left(\mathrm{m}^{3} / \mathrm{hr}\right)$

$\mathrm{T}_{2}$ = Suhu air masuk cooling tower

$\mathrm{T}_{1}$ = Suhu air keluar cooling tower

Drift loss $(W d)$ adalah kehilangan air yang disebabkan karena pengaruh gerakan fan yang berputar, besarnya sekitar 0,1-0,2\% jumlah air yang bersirkulasi. Berdasarkan desain cooling tower yang dibuat oleh PT. Hamon besarnya drift loss ditentukan sebesar :[9] $\mathrm{Wd}=0,1 \% \times \mathrm{Wc}$.

$\mathrm{Wc}=$ Debit air saat pengukuran $\left(\mathrm{m}^{3} / \mathrm{hr}\right)$

Parameter terakhir adalah blow down (Wb) yang merupakan kehilangan air akibat blowdown. Blowdown membuang sebagian air sirkulasi pekat karena proses penguapan untuk menurunkan konsentrasi padatan sistem. Blowdown diperlukan untuk membatasi pembentukan kerak air.

Besarnya nilai Blowdown (Wb) dapat ditentukan dengan persamaan berikut: 
$\mathrm{Wb}=\mathrm{We} /(\mathrm{S}-1)$

Keterangan :

$\mathrm{Wb}=$ blowdown loss

$\mathrm{S}=$ Cycle of cooling tower $(\mathrm{S}=2)$

\section{HASIL DAN PEMBAHASAN}

Tabel 1. Data desain cooling tower untuk daya nominal $30 \mathrm{MW}$

\begin{tabular}{lll}
\hline No. & Parameter & Nilai \\
\hline 1 & Cooling tower water flow & $3908,64 \mathrm{~m}^{3} / \mathrm{h}$ \\
\hline 2 & Hot water temperature & $39,20^{\circ} \mathrm{C}$ \\
\hline 3 & Cold water temperature & $32,00^{\circ} \mathrm{C}$ \\
\hline 4 & Drybulb temperature $-D B$ & $30,96^{\circ} \mathrm{C}$ \\
\hline 5 & Wet bulb temperature $-W B$ & $28,00^{\circ} \mathrm{C}$ \\
\hline 6 & Range temperature & $7,20^{\circ} \mathrm{C}$ \\
\hline 7 & $\begin{array}{l}\text { Drift loss, \% of circulating } \\
\text { flow }\end{array}$ \\
\hline 8 & $\begin{array}{l}\text { Evaporation loss, \% of } 1,15 \% \\
\text { circulating flow }\end{array}$ \\
\hline
\end{tabular}

Kemampuan pompa make-up (PA-04 AP001) yaitu $100 \mathrm{~m}^{3} / \mathrm{h}$.

Pengamatan operasi pompa make-up water (PA-04 AP001) saat reaktor beroperasi sampai daya $30 \mathrm{MW}$ pada tanggal 20 Desember 2018:

Tabel 2. Hasil pengamatan operasi pompa (PA-04 AP001), operasi 30MW, tanggal 20 Desember 2018

\begin{tabular}{|c|c|c|c|c|c|}
\hline No & Jam & $\begin{array}{l}\text { Daya } \\
\text { (MW) }\end{array}$ & $\begin{array}{l}\text { PA-04 } \\
\text { AP001 }\end{array}$ & $\begin{array}{c}\text { Level } \\
(\mathrm{m})\end{array}$ & Keterangan \\
\hline 1 & 09.24 & 25 & OFF & 4,40 & \multirow{2}{*}{$\begin{array}{c}\text { Dalam } \\
\text { waktu } 2 \text { jam } \\
9 \text { menit air } \\
\text { berkurang } \\
\text { dari level } \\
4,40 \text { ke } \\
4,18 \text { meter }\end{array}$} \\
\hline 2 & 11.33 & 30 & ON & 4,18 & \\
\hline 3 & 12.45 & 30 & OFF & 4,40 & \multirow{2}{*}{$\begin{array}{c}\text { Dalam } \\
\text { waktu } 1 \text { jam } \\
53 \text { menit air } \\
\text { berkurang } \\
\text { dari level } \\
4,40 \text { ke } \\
4,18 \text { meter }\end{array}$} \\
\hline 4 & 14.38 & 30 & ON & 4,18 & \\
\hline 5 & 15.47 & 30 & OFF & 4,40 & \\
\hline
\end{tabular}

Pengamatan operasi pompa make-up water (PA-04 AP001) saat reaktor beroperasi sampai daya $30 \mathrm{MW}$ pada tanggal 19 Maret 2019:

Tabel 3. Hasil pengamatan operasi pompa (PA-04 AP001), operasi 30MW, tanggal 19 Maret 2019

\begin{tabular}{|c|c|c|c|c|c|}
\hline No & Jam & $\begin{array}{l}\text { Daya } \\
(\mathrm{MW})\end{array}$ & $\begin{array}{l}\text { PA-04 } \\
\text { AP001 }\end{array}$ & $\begin{array}{c}\text { Level } \\
(\mathrm{m})\end{array}$ & Keterangan \\
\hline 1 & 09.48 & 15 & ON & 4,18 & \\
\hline 2 & 11.03 & 20 & OFF & 4,40 & \multirow{2}{*}{$\begin{array}{c}\text { Dalam } \\
\text { waktu } 2 \text { jam } \\
29 \text { menit air } \\
\text { berkurang } \\
\text { dari level } \\
4,40 \text { ke } \\
4,18 \text { meter }\end{array}$} \\
\hline 3 & 13.32 & 25 & ON & 4,18 & \\
\hline 4 & 14.53 & 25 & OFF & 4,40 & \multirow{2}{*}{$\begin{array}{c}\text { Dalam } \\
\text { waktu } 1 \text { jam } \\
53 \text { menit air } \\
\text { berkurang } \\
\text { dari level } \\
4,40 \text { ke } 4,18\end{array}$} \\
\hline 5 & 16.46 & 30 & ON & 4,18 & \\
\hline
\end{tabular}

\section{Perhitungan kehilangan air di cooling tower}

Kehilangan air di cooling tower dapat diakibatkan oleh terjadinya evaporasi, percikan maupun blowdown. Pada bagian ini akan dihitung kehilangan air tersebut berdasarkan desain cooling tower (teori dan kondisi yang sebenarnya).

1. Perhitungan kehilangan air berdasarkan desain yang diberikan oleh PT. Hamon::[10]

a. Perhitungan kehilangan air akibat evaporation loss (We)

Dari data desain yang diberikan oleh PT. Hamon, besarnya kehilangan air akibat evaporasi ditentukan sebesar

We $\quad=1,15 \% \times$ Wc.

Wc = Cooling tower water

flow

$$
=3908,64 \mathrm{~m}^{3} / \mathrm{h}
$$

$\mathrm{We} \quad=1,15 \% \times \mathrm{Wc}$ 


$$
\begin{aligned}
& =1,15 \% \times 3908,64 \mathrm{~m}^{3} / \mathrm{h} \\
& =44,9494 \mathrm{~m}^{3} / \mathrm{h}
\end{aligned}
$$

b. Perhitungan kehilangan air akibat drift loss (Wd)

Drift loss (Wd) adalah kehilangan air yang diakibatkan karena fan yang berputar, biasanya harganya adalah: $0,1-0,2 \%$ dari jumlah air yang bersirkulasi. Berdasarkan data desain diambil $\mathrm{Wd}=0,1 \%$

$\mathrm{Wd}=0,1 \% \mathrm{xWc}$

$\mathrm{Wc}=$ Debit air saat pengukuran $\left(\mathrm{m}^{3} / \mathrm{hr}\right)$

Keterangan : Debit air saat pengukuran diasumsikan sama dengan debit aliran dari cooling tower yaitu sebesar $3908,64 \mathrm{~m}^{3} / \mathrm{h}$. Sehingga :

$$
\mathrm{Wd}=0,1 \% \times 3908,64 \mathrm{~m}^{3} / \mathrm{h}
$$$$
=3,9086 \mathrm{~m}^{3} / \mathrm{h}
$$

c. Perhitungan kehilangan air akibat blowdown (Wb)

Blowdown yaitu membuang sebagian air yang mempunyai konsentrasi yang pekat karena proses penguapan. Dengan terjadinya blowdown maka konsentrasi air yang ada di sistem akan turun, hal ini sangat diperlukan untuk membatasi terjadinya pembentukan kerak air. Besarnya nilai Blowdown (Wb) dapat ditentukan dengan persamaan berikut:

$$
\mathrm{Wb}=\mathrm{We} /(\mathrm{S}-1)
$$

Keterangan :

We = evaporation loss

$\mathrm{S}=$ Cycle of cooling tower $(\mathrm{S}=2)$

$\mathrm{Wb}=\mathrm{We} /(\mathrm{S}-1)$
$=44,9494 /(2-1) \mathrm{m}^{3} / \mathrm{h}$

$=44,9494 \mathrm{~m}^{3} / \mathrm{h}$

d. Total kehilangan air berdasarkan desain

Berdasarkan data desain maka total kehilangan air di cooling tower adalah:

Make up water $=W e+W d+W b$ $=(44,9494+3,9086+44,9494)$

$=93,8074 \mathrm{~m}^{3} / \mathrm{h}$

2. Perhitungan berdasarkan teori

a. Perhitungan kehilangan air akibat evaporation loss(We)

Banyaknya jumlah air yang hilang akibat penguapan atau evaporation loss (We) dapat dihitung menggunakan persamaan dibawah ini:

$W e=0,00085 \mathrm{Wc}\left(\mathrm{T}_{2}-\mathrm{T}_{1}\right)$

Keterangan :

Wc = Debit air saat pengukuran

$\mathrm{T}_{2}$ = Suhu air masuk cooling

tower

$\mathrm{T}_{1}$ = Suhu air keluar cooling

tower

Hasil pengukuran saat uji fungsi cooling tower yang baru pada tanggal 20 Desember 2018, reaktor beroperasi pada daya 30 MW diperoleh data sebagai berikut:

$$
\begin{aligned}
& W \mathrm{C}=4148 \mathrm{~m}^{3} / \mathrm{h} \\
& \mathrm{T}_{2}=36,90^{\circ} \mathrm{C} \\
& \mathrm{T}_{1}=29,92^{\circ} \mathrm{C}
\end{aligned}
$$

Sehingga banyaknya kehilangan air akibat penguapan evaporation loss (We) adalah :

$$
\begin{aligned}
\mathrm{We}= & 0,00085 \mathrm{Wc}\left(\mathrm{T}_{2}-\mathrm{T}_{1}\right) \mathrm{m}^{3} / \mathrm{h} \\
= & 0,00085 \times 4148(36,9- \\
& 29,92) \mathrm{m}^{3} / \mathrm{h} \\
= & 24,61 \mathrm{~m}^{3} / \mathrm{h}
\end{aligned}
$$


b. Perhitungan kehilangan air akibat drift loss $(\mathrm{Wd})$

$\mathrm{Wd}=0,1 \% \times \mathrm{Wc}$

$\mathrm{Wc}=$ Debit air saat pengukuran $\left(\mathrm{m}^{3} / \mathrm{hr}\right)$

Keterangan : Debit air saat pengukuran diasumsikan sama dengan debit aliran dari cooling tower yaitu sebesar $3908,64 \mathrm{~m}^{3} / \mathrm{h}$.

Wd $=0,1 \% \times 3908,64 \mathrm{~m}^{3} / \mathrm{h}$

$$
=3,9086 \mathrm{~m}^{3} / \mathrm{h}
$$

Sehingga banyaknya jumlah kehilangan air yang diakibatkan oleh drift loss (Wd) sebesar $3,90864 \mathrm{~m}^{3} / \mathrm{h}$.

c. Perhitungan kehilangan air akibat blowdown $(\mathrm{Wb})$

Perhitungan berdasarkan hasil pengukuran

$$
\begin{aligned}
\mathrm{Wb} & =\mathrm{We} /(\mathrm{S}-1) \\
& =24,61 /(2-1) \mathrm{m}^{3} / \mathrm{h} \\
& =24,61 \mathrm{~m}^{3} / \mathrm{h}
\end{aligned}
$$

d. Berdasarkan perhitungan maka total kehilangan air di cooling tower adalah:

$$
\begin{gathered}
\text { Make up water }=W e+W d+W b \\
=(24,61+3,9086+24,61) \\
=53,1286 \mathrm{~m}^{3} / \mathrm{h}
\end{gathered}
$$

3. Perhitungan berdasarkan hasil pengamatan

Hasil pengamatan operasi pompa PA-04 yang dilakukan pada tanggal 20 Desember 2018 dan 19 Maret 2019, yaitu saat reaktor beroperasi pada daya $30 \mathrm{MW}$. Rata-rata dalam waktu 2 jam terjadi terjadi penurunan ketinggian air cooling tower dari level 4,40 meter ke 4,18 meter. Berdasarkan penurunan ketinggian air di cooling tower maka dapat dihitung volume air yang berkurang dalam waktu 2 jam. Penurunan ketinggian air
$(\Delta \mathrm{t})=4,40-4,18$ meter $=0,22$ meter, lebar kolam $(\mathrm{I})=16,8$ meter, dan panjang kolam $(p)=21,35$ meter maka volume air yang berkurang adalah;

$$
\begin{aligned}
\text { Volume } & =\mathrm{p} \times \mathrm{I} \times \Delta \mathrm{t} \\
= & 21,35 \mathrm{~m} \times 16,8 \mathrm{mx} \\
& 0,22 \mathrm{~m} \\
= & 78,9096 \mathrm{~m}^{3}
\end{aligned}
$$

Sehingga dalam waktu 2 jam maka besarnya keperluan make up water di cooling tower adalah:

$$
\begin{aligned}
\text { make up water } & =\text { volume }: \text { waktu } \\
& =78,9096 \mathrm{~m}^{3}: 2 \mathrm{jam} \\
& =39,4548 \mathrm{~m}^{3} / \mathrm{h} .
\end{aligned}
$$

\section{KESIMPULAN}

Berdasarkan data desain cooling tower yang baru, hasil perhitungan kehilangan air, hasil pengamatan operasi pompa PA04 dapat disimpulkan bahwa:

1. Kehilangan air di cooling tower pada kondisi reaktor beroperasi pada daya $30 \mathrm{MW}$ masih lebih kecil dibandingkan dengan perhitungan maupun hasil desain, sehingga dapat disimpulkan bahwa cooling tower masih aman.

2. Dengan kapasitas pompa PA-04 sebesar $100 \mathrm{~m}^{3} / \mathrm{h}$ dan kehilangan air sebesar $39,4548 \mathrm{~m}^{3} / \mathrm{h}$ maka pompa tersebut masih mampu untuk memenuhi kebutuhan make up air dalam mengkompensasi kehilangan air di cooling tower.

\section{DAFTAR PUSTAKA}

1. G. B. HILL E. J. PRING PETER D. OSBORN: Cooling Towers, 3rd Edition: Principles and Practice, Butterworth-Heinemann, 1990.

2. Gerald Bowen Hill, E. J. Pring, Peter David Osborn, William Stanford: Cooling towers: principles and 
practice, Butterworth-Heinemann, 1990.

3. https://www.cti.org/downloads/win09jo urnal.pdf

4. Muhammad Awwaluddin, Puji Santosa, Suwardiyono, Pusat Rekayasa Perangkat Nuklir - BATAN: Perhitungan Kebutuhan Cooling Tower Pada Rancang Bangun Untai Uji Sistem Kendali Reaktor Riset, PRIMA, Volume 9, Nomor 1, Juni 2012 ISSN : 1411-0296.

5. Hutriadi Pratama Siallagan: Analisis Kinerja Cooling Tower 8330 CT01 Pada Water Treatment Plant-2 PT KRAKATAU STEEL (Persero). Tbk, Jurnal Teknik Mesin (JTM): Vol. 06, No. 3, Juni 2017.
6. https://www.researchgate.net/publicati on/317829430 Cooling towers Estim ate evaporation loss and makeup water requirements.

7. https://checalc.com/solved/ctmakeup. html

8. U. Vengateson National Petrochemical Co. (Saudi Arabia): Engineering Practice: Cooling Towers: Estimate Evaporation Loss and Makeup Water Requirements.

9. Manufacturer data record by PT Fulgurindo Teknik Utama, PT Hamon Indonesia; Project: Pekerjaan pengadaan sistem cooling tower, Pusat Reaktor Serba Guna (PRSG) tahun 2018.

10.PT Hamon Indonesia; Cooling tower performance test procedure. 